\title{
Analysis of heart rate variability in individuals subjected to different positive end expiratory pressure levels using expiratory positive airway pressure
}

\author{
Thiago Lorentz Pinto ${ }^{1}$, Luciana Maria Malosá Sampaio ${ }^{1}$, Ivan Peres Costa ${ }^{1}$, \\ Leandro Yukio Alves Kawaguchi', Flávio Aimbire Soares de Carvalho², Regiane Albertini de Carvalho ${ }^{1}$
}

${ }^{1}$ Nove de Julho University, Sao Paulo, Brazil

2UNIFESP Universidade Federal de Săo Paulo, Brazil

Submitted: 8 November 2011

Accepted: 11 May 2012

Arch Med Sci 2013; 9, 4: 651-655

DOI: 10.5114/aoms.2013.36902

Copyright @ 2013 Termedia \& Banach

\begin{abstract}
Introduction: The increase in the number of studies has led to greater security in the application of this method and the determination of its effectiveness in adults.. The purpose of the present study was to evaluate heart rate variability in healthy individuals submitted to different levels of positive expiratory pressure using an expiratory positive airway pressure (EPAP) device.

Material and methods: The study involved 27 healthy male individuals ranging in age from 20 to 35 years. Patient histories were taken and the subjects were submitted to a physical examination. The volunteers were monitored using the Polar $810 \mathrm{~s} \circledast$ and submitted to the EPAP experiment. Analyses were performed on variables of the frequency domain. Sympathetic and parasympathetic bands and their relationship with sympathovagal response were also analyzed.

Results: The mean value of this variable was 526.89 (55.50) $\mathrm{ms}^{2}$ in the first period, 2811.0 (721.10) $\mathrm{ms}^{2}$ in the fourth period and 726.52 (123.41) $\mathrm{ms}^{2}$ in the fifth period. Regarding the parasympathetic area, significant differences were detected when Periods 1 and 5 (no load) were compared with periods in which the individuals were subjected to the use of the therapy. Sympathetic and parasympathetic areas together, a significant difference was detected regarding the sympathetic/parasympathetic ratio in the comparison between Periods 1 and $4(p<0.01)$ as well as Periods 2 and $4(p<0.05)$.

Conclusions: The findings of the present study suggest that the therapeutic use of EPAP significantly alters the parameters of heart rate variability in the frequency domain, highlighting the importance of monitoring and care during the practice of EPAP.
\end{abstract}

Key words: heart rate variability, positive expiratory pressure, healthy individuals.

\section{Introduction}

In the past, the most widely employed non-invasive respiratory interfaces were nasal and oronasal masks. Aside from intensive care units, nasal masks were used for ventilating patients with chronic obstructive pulmonary disease and the application of continuous positive airway pressure (CPAP) in those with obstructive sleep apnea. With the advent of the portable ventilator and biphasic operating with support pressure for obstructive sleep apnea, the potential for ventilation for other purposes has been recognized. The main advantage of noninvasive positive pressure is the

\author{
Corresponding author: \\ Luciana Maria Malosá \\ Sampaio PhD \\ UNINOVE \\ Nove de Julho University \\ Av Francisco Matarazzo 612 \\ 00550000 Sao Paulo \\ Brazil \\ Phone: 55-11-35892792, \\ 55-11-36659325 \\ E-mail: \\ lucianamalosa@terra.com.br
}


avoidance of endotracheal intubation and associated complications. Other benefits include increased comfort, reducing need for sedation, preservation of speech and swallowing, preservation of upper airway functions, such as heating and humidifying inspired air, preservation of the defense functions of the mucociliary system, a lower incidence of barotraumas and a reduced need for enteral nutrition, as the patient's swallowing capacity is unaffected. However, enteral nutrition can be maintained, if needed, with the tube set in the mask.

Noninvasive positive pressure can also be used in home care for patients with cardiovascular, respiratory, central nervous system, neuromuscular and skeletal disorders. Despite the frequent use of EPAP, the literature on this subject is scarce, especially with regard to the adverse effects $[1,2]$. Respiration exerts a significant influence over autonomic cardiovascular control. During normal breathing, oscillations in ventricular volume and systemic blood pressure occur, which are detected by baroreceptors, leading to changes in RR intervals. Since these hemodynamic fluctuations during breathing (negative pressure) are predominantly due to changes in intrathoracic pressure, EPAP should be used with caution in patients with heart and lung diseases.

Current advances in bioengineering and the processing of biological signals have led to numerous opportunities for novel non-invasive therapeutic procedures as well as an increased diagnostic capacity, especially in the cardiovascular field $[3,4]$. Thus, a form of cardiovascular diagnosis that merits attention is the analysis of heart rate variability (RR interval) performed by a computer, which offers real possibilities of observation regarding biological signals and the understanding of the extrinsic control of heart rate.

Despite being widespread in Brazil, the use of EPAP as a physical therapy technique has been studied little [5]. Few studies have evaluated heart rate variability (HRV) in healthy individuals submitted to different PEEP levels and no studies have evaluated HRV when different pressure levels are established using EPAP $[4,6]$.

Thus, the aims of the present study were to evaluate HRV in healthy individuals submitted to different positive end expiratory pressure (PEEP) levels using EPAP and investigate the application of this therapeutic resource with the hope of establishing safer therapeutic interventions.

\section{Material and methods}

\section{Study design and patient population}

The subjects were 30 healthy male volunteers between 20 and 35 years of age with no present history of smoking, body mass index (BMI) between $18 \mathrm{~kg} / \mathrm{m}^{2}$ and $30 \mathrm{~kg} / \mathrm{m}^{2}$, with no cognitive impair- ment that would compromise the achievement of the evaluation procedures and having signed a consent form. The study received approval from the Ethics Committee of the Universidade do Vale do Paraiba (Brazil) under process number H18/CEP2008. Individuals with a history of heart disease, coronary artery disease or any condition that would affect the results and those who failed to perform the procedures were excluded from the study.

The individuals selected underwent an evaluation that included a medical history and physical examination. The International Physical Activity Questionnaire (version 8) was used to classify the activity level of each participant. This questionnaire has been validated for the Brazilian population [7]. Based on the criteria of frequency, duration and type of physical activity, the volunteers were classified as sedentary, insufficiently active, active or very active [7].

\section{Experimental procedure}

The volunteers were first familiarized with the experimental environment and researchers involved in the study. Prior to beginning the tests, the participants were interviewed to ensure compliance with medication instructions and examined. Systolic and diastolic blood pressure, pulmonary auscultation and peripheral oxygen saturation $\left(\mathrm{SpO}_{2}\right)$ were all assessed. A single data collection session was required for each subject.

Each participant was instructed to sit in a chair with hips and knees flexed at $90^{\circ}$, feet flat on the floor and elbows on a table. EPAP was conducted with a PEEP valve (spring-loaded, portable, clear plastic, ranging from $5 \mathrm{~cm} \mathrm{H} \mathrm{H}_{2} \mathrm{O}$ and $20 \mathrm{~cm} \mathrm{H}_{2} \mathrm{O}$, unidirectional flow and silicone face mask).

The EPAP obeyed the following load sequence: PEEP $5 \mathrm{~cm} \mathrm{H}_{2} \mathrm{O}$, PEEP $10 \mathrm{~cm} \mathrm{H} \mathrm{H}_{2} \mathrm{O}$ and PEEP $15 \mathrm{~cm}$ $\mathrm{H}_{2} \mathrm{O}$. The measurements were carried out for $3 \mathrm{~min}$ at each load, with no breaks. Heart rate variability was collected using the Polar ${ }^{\circledR} 8105$ monitor throughout the experimental period, including 3 min before and 3 min after the completion of the sequence. The transmitter was placed on the sixth costal line of the individual at the height of the xiphoid process. Total collection time was $15 \mathrm{~min}$, divided into five periods (Table I).

All collections were started at 3:00 pm at room temperature at least $2 \mathrm{~h}$ after a light meal. The participants were instructed not to ingest alcohol or coffee for at least $6 \mathrm{~h}$ prior to the test [8].

\section{Heart rate variability analysis}

Heart rate variability was analyzed in the time and frequency domains using an algorithm developed in MatLab (version 6.1, 450 Release 12.1). The section of highest stability, which included a simple line comprised of at least 256 points, was select- 
Table I. Periods, times and loads during experiment

\begin{tabular}{|lccccc|}
\hline Period & 1 & 2 & 3 & 4 & 5 \\
\hline Time & $0-3 \mathrm{~min}$ & $3-6 \mathrm{~min}$ & $6-9 \mathrm{~min}$ & $9-12 \mathrm{~min}$ & $12-15 \mathrm{~min}$ \\
\hline Load & No load & $5 \mathrm{~cm} \mathrm{H}_{2} \mathrm{O}$ & $10 \mathrm{~cm} \mathrm{H}_{2} \mathrm{O}$ & $15 \mathrm{~cm} \mathrm{H}_{2} \mathrm{O}$ & $\mathrm{No} \mathrm{load}$ \\
\hline
\end{tabular}

ed from R-R intervals by visual inspection based on the criteria set forth by the Task Force of the European Society of Cardiology and the North American Society of Pacing and Electrophysiology [8].

Time domain analysis was calculated from the RMSSD index [the square root of the sum of the squares of the differences between adjacent normal-to-normal (NN) intervals] and the SDNN (standard deviation of NN intervals) [9]. Frequency domain analysis employed the fast Fourier transform of the time series. The application of this algorithm permitted the identification of the power spectral density as well as its frequency bands: very low frequency, low frequency (LF) and high frequency (HF). Two frequency bands that best represent the vagal and sympathetic activity of HR control were used in this study. Signals in the LF band $(0.04 \mathrm{~Hz}$ to $0.15 \mathrm{~Hz})$ have been predominately attributed to high sympathetic tones and low parasympathetic tones. Signals in the HF band (0.15 to 0.4) have been attributed only to parasympathetic activity [9]. Spectral components were obtained in both absolute (ms) ${ }^{2}$ and normalized units (nu) [9].

Time and frequency analysis of the R-R intervals acquired during respiratory sinus arrhythmia maneuver (RSA-M) was then performed. Additionally, the spectral analysis confirmed that all volunteers maintained a respiratory rate between 5 and 6 cycles/ min, which corresponds to a peak spectral density frequency between $0.08 \mathrm{~Hz}$ and $0.1 \mathrm{~Hz}$. Another specific routine developed in MatLab was used to calculate the HR and R-R interval indices of RSA-M [10], i.e., the expiratory/inspiratory ratio $(E / I)$, which is the mean of the longest R-R interval values obtained during the expiratory phase divided by the mean of the shortest R-R interval values obtained during the inspiratory phase, and the inspiratory-expiratory difference $(\Delta \mathrm{IE})$, which is the difference between the mean of the highest HR value obtained during the inspiratory phase and the mean of the lowest HR value obtained during the expiratory phase.

Finally, the data obtained by HRV analysis in the time and frequency domains as well as the HR and $R$ - $R$ interval values of RSA-M were transformed into decimal logarithms for the purposes of statistical analysis.

\section{Statistical analysis}

The Kolmogorov-Smirnov test of normality was used to determine whether the statistical analysis would be parametric or nonparametric. In the analysis of time periods with respect to each variable in both the time and frequency domains, the TukeyKramer multiple comparison test (ANOVA with Tukey's contrast test) was employed, with the level of significance set at $p \leq 0.05$.

\section{Results}

All volunteers were classified as either sedentary or insufficiently active. Therefore, there was no need for the differentiation of this variable in the statistical analysis, as the possibility of major changes in the behavior of HRV being due to different levels of fitness was discarded. Table II displays the descriptive statistics characterizing the sample, such as age, weight, height, body mass index (BMI), systolic blood pressure and diastolic blood pressure.

Figures 1-3 illustrate the variables of the frequency domain (sympathetic area, parasympathetic area and sympathetic-parasympathetic ratio). A significant increase $(p<0.001)$ was found in the sympathetic area when comparing Periods 1 and 4 and a significant reduction $(p<0.001)$ was found when comparing Periods 4 and 5 (Figure 1). The mean value of this variable was $526.89 \pm 55.50 \mathrm{~ms}^{2}$ in the first period, $2811.0 \pm 721.10 \mathrm{~ms}^{2}$ in the fourth period

Table II. Descriptive measures of age, weight, height, BMI and systolic and diastolic blood pressure

\begin{tabular}{|c|c|c|c|c|c|c|}
\hline \multirow[t]{2}{*}{ Variable } & \multirow[t]{2}{*}{$N$} & \multicolumn{5}{|c|}{ Descriptive measures } \\
\hline & & Minimum & Maximum & Median & Mean & SD \\
\hline Age [year] & 27 & 20 & 35 & 27 & 26.78 & 3.77 \\
\hline Weight $[\mathrm{kg}]$ & 27 & 53 & 98 & 74.5 & 74.21 & 10.13 \\
\hline Height $[\mathrm{m}]$ & 27 & 1.60 & 1.89 & 1.75 & 1.75 & 0.06 \\
\hline $\mathrm{BMI}\left[\mathrm{kg} / \mathrm{m}^{2}\right]$ & 27 & 19.06 & 29.08 & 24.2 & 24.11 & 2.58 \\
\hline Systolic pressure [mm Hg] & 27 & 110 & 130 & 120 & 119.28 & 6.48 \\
\hline Diastolic pressure [mm Hg] & 27 & 55 & 80 & 70 & 71.96 & 8.64 \\
\hline
\end{tabular}




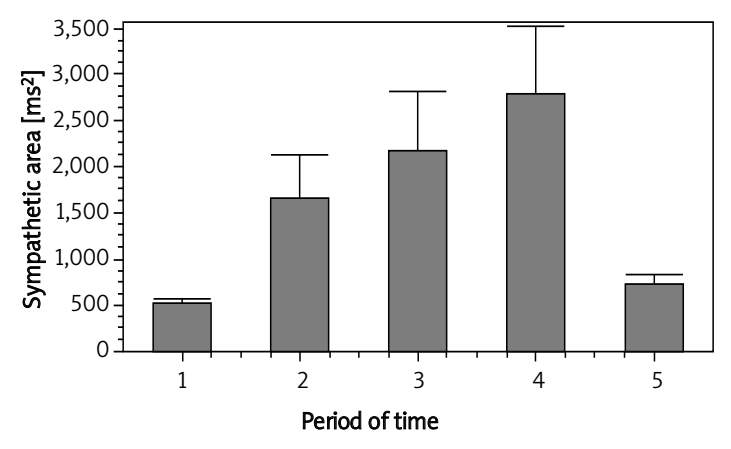

Figure 1 . Mean \pm standard error values of sympathetic band in five periods of time

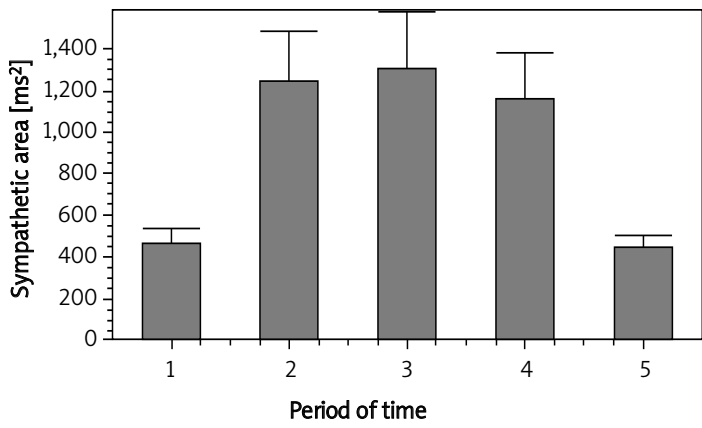

Figure 2. Mean \pm standard error values of parasympathetic band in five periods of time

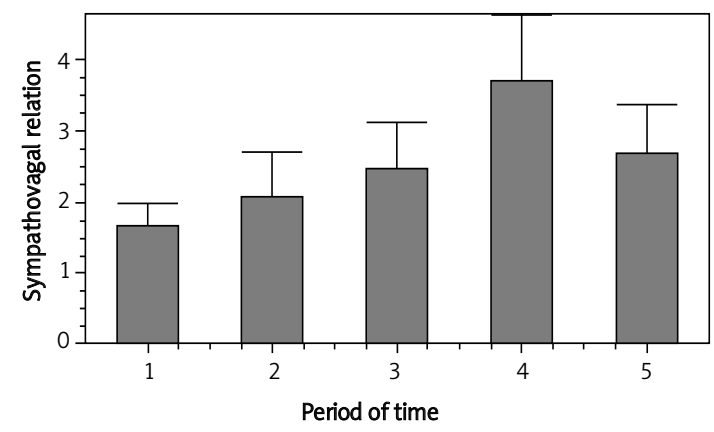

Figure 3. Mean \pm standard error values of sympathovagal ratio in five periods of time

and $726.52 \pm 123.41 \mathrm{~ms}^{2}$ in the fifth period. Regarding the parasympathetic area, significant differences were detected when Periods 1 and 5 (no load) were compared with periods in which the individuals were subjected to the use of the therapy. Observing sympathetic and parasympathetic areas together, a significant difference was detected regarding the sympathetic/parasympathetic ratio in the comparison between Periods 1 and $4(p<0.01)$ as well as Periods 2 and $4(p<0.05)$ (Figure 3$)$. The mean value of this ratio was $1.67 \pm 0.28$ in the first period, $2.08 \pm 0.62$ in the second period and $3.71 \pm 0.94$ in the fourth period (Figures 1-3).

\section{Discussion}

As mentioned in the introduction of the present study, there are no scientific studies relating the use of EPAP and HRV. However, the conditions for positive airway pressure generated by this device can be compared (with some caution) to conditions offered by devices that generate airflow and therefore increase blood pressure.

In a study involving 16 men with congestive heart failure, Butler et al. [11] found that CPAP in the airways increased HRV in both the time and frequency domains. According to the authors, different mechanisms may contribute to this increase, such as the mechanical or reflex effects of lung inflation. The authors found no significant change in RR intervals. In the present study, however, there was a significant reduction in this interval, resulting in a significant increase in heart rate when the device was initiated. This may be explained by the different techniques applied. As stated above, EPAP supplies pressure in the airways during expiration, whereas CPAP provides continuous pressure during both expiration and inspiration, which reduces the respiratory work and maintains the heart rate steady.

Garet et al. [12] evaluated healthy individuals using positive pressure and found a significant reduction in parasympathetic stimulation after the withdrawal of positive airway pressure. The results of the present study corroborate these results.

Valipour et al. [8] conducted a study involving healthy individuals in which PEEP was set up through CPAP and found results different from those reported here. In the study, ten volunteers (5 men and 5 women) were evaluated and a significant reduction in the parasympathetic area was observed. The same limiting factor can be applied to both the study cited and the present investigation, namely, the difficulty in controlling the respiratory rate, which is a factor that exerts a significant influence over HRV [13]. However, the factors that could explain the differences in results between studies are the method of providing positive pressure, the inclusion of women in the sample and the small number of volunteers studied.

The increase in the parasympathetic area, which is well supported and demonstrated in the literature, was one of the results of the present study. However, there was also an increase in sympathetic stimulation, which has been described elsewhere. We suggest that this stimulation is due to the increased respiratory work caused by the use of EPAP. Macefield [14] suggests that the increase in intrathoracic pressure during inflation of the lungs increases sympathetic activity due to the unloading of baroreceptors by reducing cardiac filling pressures. Similar results are reported by Ikeda et al. [15] and Heindl et al. [16]. In this context, the results obtained in the present study seem justified when analyzed in light of those reported in the literature.

The results of the present study underscore the importance of monitoring and care during the use 
of EPAP, particularly in cases of tachycardia and arrhythmia. One of the limitations of the present study was the difficulty in finding literature for a more specific grounding of the results. Thus, there is a need for further studies that can better characterize and confirm these hypotheses and extrapolate this analysis to patients with specific diseases.

In conclusion, the results of the present study demonstrate that EPAP significantly alters heart rate variability parameters in the frequency domain.

\section{References}

1. Keenan SP, Sinuff T, Cook DJ, Hill N. Which patients with acute exacerbation of chronic obstructive pulmonary disease benefit from noninvasive positive-pressure ventilation? A systematic review of the literature. Ann Intern Med 2003; 138: 861-70.

2. Yang $M$, Yuping $Y$, Yin X, et al. Chest physiotherapy for pneumonia in adults. Cochrane Database Syst Rev 2010; 2: CD006338.

3. Malik M, Writing C. Heart rate variability. Standards of measurement, physiocological interpretation, and clinical use. Eur Heart J 1996; 17: 354-81.

4. Ribeiro MP, Brum JM, Ferrario CM. Análise espectral da freqüencia cardíaca - conceitos básicos e aplicação clínica. Arquivos Brasileiros de Cardiologia 1992; 59: 141-50.

5. Publio AZ, Tuzi DA, Possoni HC, Rocha SM. Estudo da pressão positiva expiratória a sua eficácia na atelectasia: uma revisão literária. Fisioterapia em Movimento 2004; 17: 43-50.

6. Oliveira DJ, Gomes MED, Aguirre LA. Análise da variabilidade da freqüencia cardíaca baseada no estudo de modelos identificados. In: Congresso Brasileiro De Engenharia Biomédica, 18. 2002, São José dos Campos. Anais... São José dos Campos: UNIVAP 2002; 355-9.

7. Matsudo S, Araújo T, Matsudo V, Andrade D, Andrade E, Oliveira LC. Questionário internacional de atividade física (IPAC): estudo de validade e reprodutibilidade no Brasil. Revista Brasileira de Atividade Física e Saúde 2001; 6: 5-18.

8. Valipour A, Schneider F, Kössler W, Saliba S, Burghuber OC. Heart rate variability and spontaneous baroreflex sequences in supine healthy volunteers subjected to nasal positive airway pressure. J Appl Physiol 2005; 99 : 2137-43.

9. Task Force of European Society of Cardiology and the North American Society of Pacing and Electrophysiology. Heart rate variability: standards of measurement, physiological interpretation, and clinical use. Circulation 1996; 93: 1043-65.

10. O'Brien IA, O'Hare P, Corrall RJM. Heart rate variability in healthy subjects: effect of age and the derivation of normal ranges for tests of autonomic function. $\mathrm{Br}$ Heart J 1986; 55: 348-54.

11. Butler GC, Naughton MT, Rahman MA, Bradley TD, Floras JS. Continuous positive airway pressure increases heart rate variability in congestive heart failure. J Am Coll Cardiol 1995; 25: 672-9.

12. Garet M, Barthelemy JC, Degache F, Pichot V, Duverney D, Roche, F. Modulations of human autonomic function inducedby positive pressure - assisted breathing. Clin Physiol 2006; 26: 15-20.

13. Pöyhönen M, Syvaoja S, Hartikainen J, Ruokonen E. The effect of carbon dioxide, respiratory rate and tidal volume on human heart rate variability. Acta Anaesthesiol Scand 2004; 48: 93-101.

14. Macefied VG. Sustained activation of muscle sympathetic outflow during static lung inflation depends on a high intrathoracic pressure. J Autonomic Nervous System 1998; 68: 135-9.

15. Ikeda T, Iwase S, Saito M, Mano T. Effects of positive and negative pressure breathing on muscle sympathetic nerve activity in humans. Aviation, Space, and Environmental Medicine 1997; 68: 494-8.

16. Heindl S, Dodt C, Krahwinkel M, Hasenfuss G, Andreas S. Short term effects of continuous positive airway pressure on muscle sympathetic nerve activity in patients with chronic heart failure. Heart 2001; 85: 185-90. 